\title{
Dipole Antenna With Integrated Balun For Ultra- wideband Radio 6-9 GHz
}

Magnus Karlsson, Owais Owais, J oakim Östh, Adriana Serban, Shaofang Gong, Magnus J obs and Mathias Gruden

The self-archived postprint version of this journal article is available at Linköping University Institutional Repository (DiVA):

http://urn.kb.se/ resolve?urn=urn:nbn:se:liu:diva-64238

N.B.: When citing this work, cite the original publication.

Karlsson, M., Owais, O., Östh, J., Serban, A., Gong, S., J obs, M., Gruden, M., (2011), Dipole Antenna With Integrated Balun For UItra-wideband Radio 6-9 GHz, Microwave and optical technology letters (Print), 53(1), 180-184. https:// doi.org/ 10.1002/ mop.25656

Original publication available at:

https:/ / doi.org/ 10.1002/ mop.25656

Copyright: Wiley (12 months)

http:// eu.wiley.com/WileyCDA/ 


\title{
Circular Dipole Antenna with Integrated Balun for Ultra-wideband Radio 6-9 GHz
}

\author{
Magnus Karlsson, Owais, Joakim Östh, Adriana Serban, Shaofang Gong, Member, IEEE, Magnus Jobs \\ and Mathias Grudén
}

\begin{abstract}
A fully integrated dipole antenna with a balun for ultra-wideband (UWB) radio in the band 6-9 $\mathbf{G H z}$ utilizing a flexible and rigid printed circuit board is presented in this paper. The balun utilizes broadside-coupled microstrips and is integrated in the rigid part of the printed circuit board, while the radiator is placed in the flexible part. The antenna with the balun covers the frequency-band $6.0-8.5 \mathrm{GHz}$ at $\mathrm{VSWR}<2.0$, and 5.511.0 GHz at $V S W R<2.5$. Moreover, simulated and measured radiation patterns, and antenna efficiency above $86.0 \%$ is observed.
\end{abstract}

Index Terms-Balun, broadside-coupled, circular, dipole antenna, UWB, Ultra-wideband

\section{INTRODUCTION}

I nitially the frequency-band 3.1-10.6 GHz was opened for commercial use of ultra-wideband (UWB) radio by the Federal Communications Committee (FCC) [1]-[13]. In the beginning the 3.1-4.8 GHz, also known as the Mode 1 band group quickly became the primary frequency-band. Later on legal respiratory around the world has adopted additional constraints on the use of the UWB frequency-band [9]-[11]. As a result the frequency-bands 6-8.5, 6-9, and 6-10.6 GHz have lately received an increased attention [10]-[11].

Until present many promising ideas for wideband antennas with omni-directional pattern and linear phase have been presented [14]-[33]. For instance, contributions in band control and notching have been achieved [26], [28], [33]. However, the scope has so far been mostly of performance of the antenna element, wireless link properties, but not so much on how the antenna can be used and integrated in a UWB system. To address this problem the authors proposed a fully integrated dipole antenna with a balun on flex-rigid substrate [12]. Using this flex-rigid concept the antenna is made on the flexible part of the flex-rigid structure, and in the rigid part the integrated balun provides a good electrical conversion to single-ended $50-\Omega$ systems.

However, our previously presented antenna is for Mode 1 UWB [12], i.e., 3.1-4.8 GHz. In this paper an antenna for the 6-9 $\mathrm{GHz}$ frequency band is presented. Furthermore, in this

Ericsson AB, Sony Ericsson Mobile Communications AB and Vinnova in Sweden are acknowledged for financial support of this work.

M. Karlsson; email: magka@itn.liu.se, Owais, J. Östh, A. Serban, S. Gong are with the Dep. of Science and Technology, Communication Electronics Group at Linköping University, Sweden. M. Jobs and M. Grudén are with the Dep. of Engineering Sciences, Microwave Group at Uppsala University, Sweden. paper measured full $360^{\circ}$ radiation patterns and antenna efficiency are presented. A wheeler cap [34] was used to perform the antenna efficiency measurements. Moreover, additional details are given and explained about the flex-rigid printed circuit board build-up.
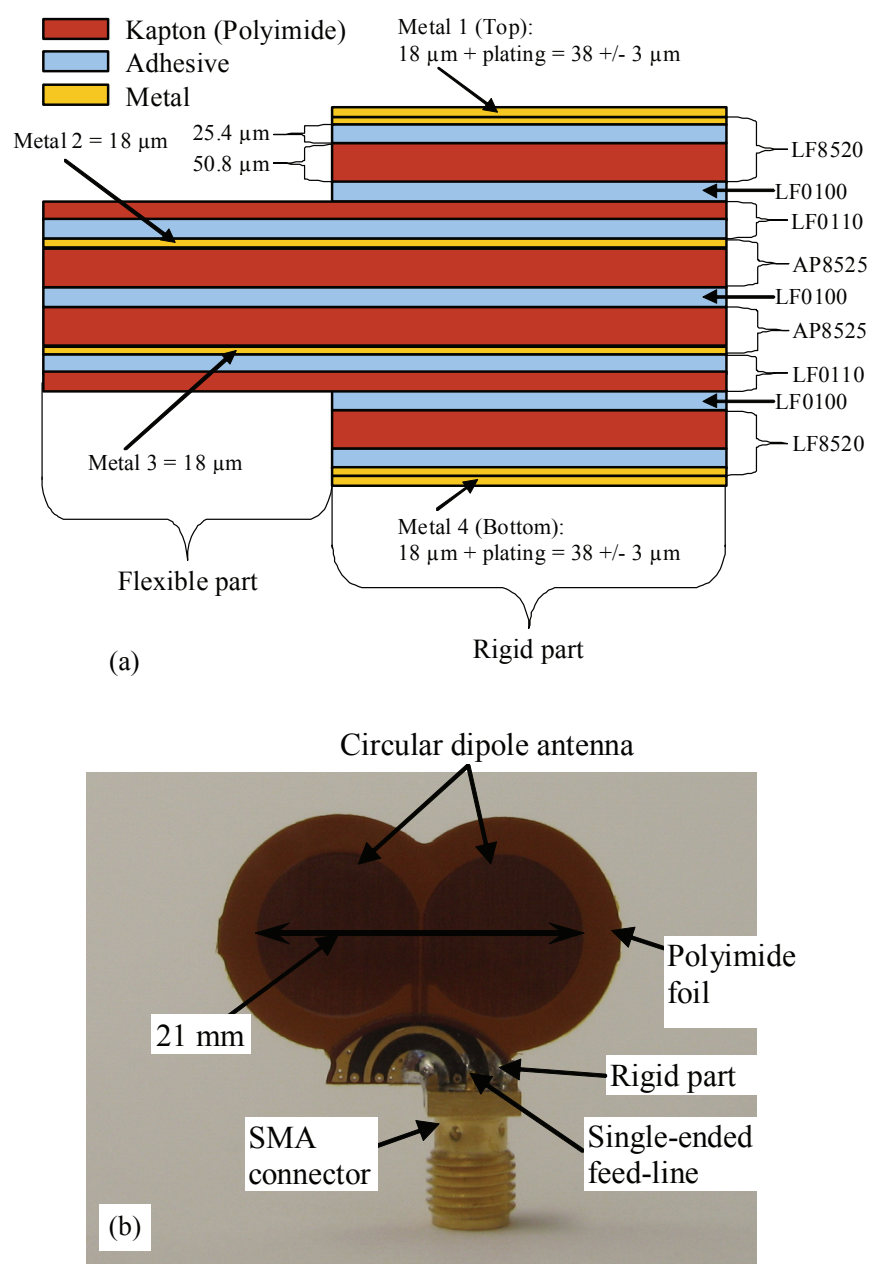

Fig. 1. Circular dipole antennas: (a) Substrate build-up, and (b) photo of the antenna positioned in the $\mathrm{x}-\mathrm{y}$ plane.

\section{OVERVIEW OF THE SYSTEM}

As shown in Fig. 1(a) the prototype was manufactured using a flex-rigid printed circuit board (two metal-layers in the flexible part and four in the rigid part). The LF8520, LF0100, LF0110 and AP8525 are from DuPont ${ }^{\mathrm{TM}}$ Pyralux ${ }^{\circledR}$ laminate series. The rigid and the flexible substrates are processed 
together in a printed circuit board bonding process, i.e., the adhesive layers are used to bond the polyimide layers.

\section{A. Circular dipole antenna}

Fig. 1(b) shows a circular dipole antenna realized using the flex-rigid substrate. The antenna is positioned in the $x-y$ plane, and $\phi=0$ (Horizontal plane) is along the $x$-axis. It is seen that the radiating antenna element is placed entirely on the flexible part of the substrate. Furthermore, the balun is integrated in the rigid part of the substrate. The backside of the rigid part (Metal 4) is completely covered with metal to make throughboard ground vias possible, and to provide additional solderable ground-junctions for the SMA connector. Drilled vias with a diameter of $0.3 \mathrm{~mm}$ are used for grounding.

\section{B. The distributed balun used with the dipole antenna}

Fig. 2 shows an illustration of the broadside-coupled balun. The balun is used together with the dipole antennas and built with the broadside-coupled microstrips [15], [34]. By implementing the balun in a multilayer structure a more compact design is achieved. The single-ended microstrip-line is placed on Metal layer 1. The differential microstrip-line of the balun is placed on Metal layer 2, directly beneath the microstrip-line on Metal-layer 1. The two lines then exhibit a strong broadside-coupling, and since the arm ends of the differential line are grounded at their ends there is a $180^{\circ}$ phase-shift between Port 2 and 3. Metal 2 is also the metallayer where the radiator is placed, i.e., the differential feedline is directly routed to the antenna [12].

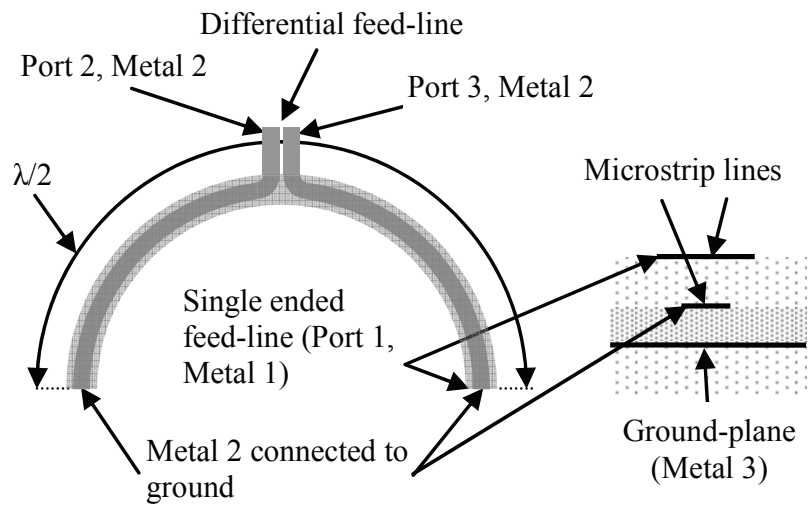

Fig. 2. Layout and cross-section of the broadside-coupled balun.

\section{RESULTS}

Design and simulation were done with ADS2008 (Update 2) from Agilent Technologies Inc. Electromagnetic simulations were done with Momentum, a built-in 2.5D field solver of method of moment.

\section{A. Impedance bandwidth}

Fig. 3 shows voltage standing wave ratio (VSWR) simulations and measurements of the circular dipole antennas on the flex-rigid substrate. The VSWR simulation and measurement results with the balun are shown. It is seen in the simulated and measured results in Fig. 3 that the circular dipole antenna has a wide impedance bandwidth (VSWR $<2.0$ in the 6.0-8.5 GHz frequency-band). Furthermore, it is seen that the antenna has a VSWR $<2.5$ bandwidth from 5.5 to 11.0 $\mathrm{GHz}$. A small shift in frequency is also seen which is likely due to the fact that the simulated phase velocity is lower than the actual.

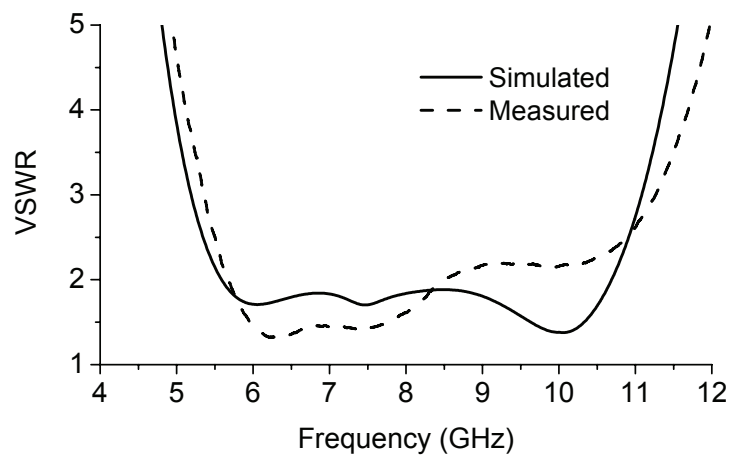

Fig. 3. Circular dipole antenna VSWR simulation and measurement with balun.

\section{B. Radiation pattern}

It is seen in Fig. 4(a)-(e) that the antenna has a wide-angled radiation pattern, and that the simulated results correlate well with the measured results. Fig. 4(a)-(c) shows the $\phi=0^{\circ}$ (Horizontal plane) radiation pattern at $6.5,7.5$ and $8.5 \mathrm{GHz}$, respectively. Some disagreement between simulation and measurement are observed. In the front half-sphere (upper half) the agreement is good, but in the lower half-sphere some disagreements exist. This is likely due to the fact that the electromagnetic field couples to the ground of the SMAconnector and the ground-plane in the rigid part (in Metal layer 3, while the antenna is placed in Metal layer 2 in the flexible part). Fig. 4(d) and (e) shows the $\phi=90^{\circ}$ (Vertical plane) radiation pattern at 6.5 and $8.5 \mathrm{GHz}$, respectively. The vertical radiation patterns show similar relation between simulation and measurement as the horizontal radiation patterns. For instance, a small peak around $210^{\circ}$, i.e., a minor ground back-up effect when the SMA-connector is diagonally behind the radiator.

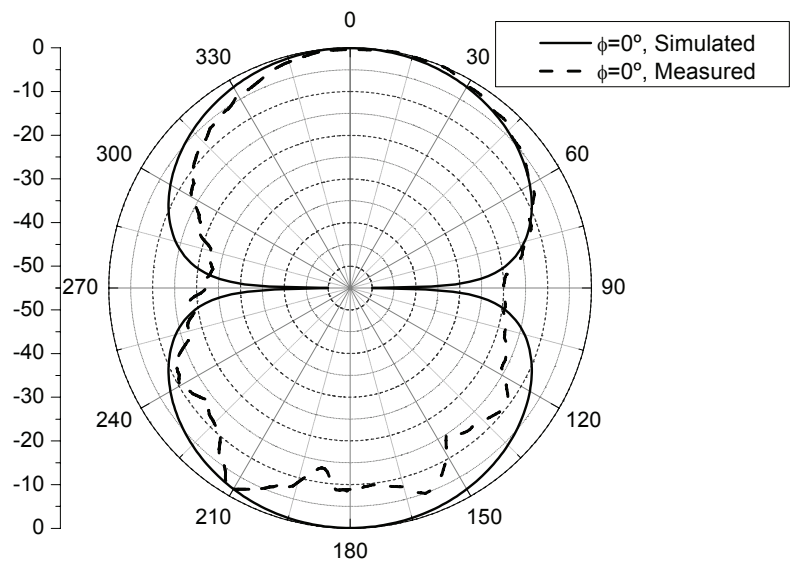

(a) 


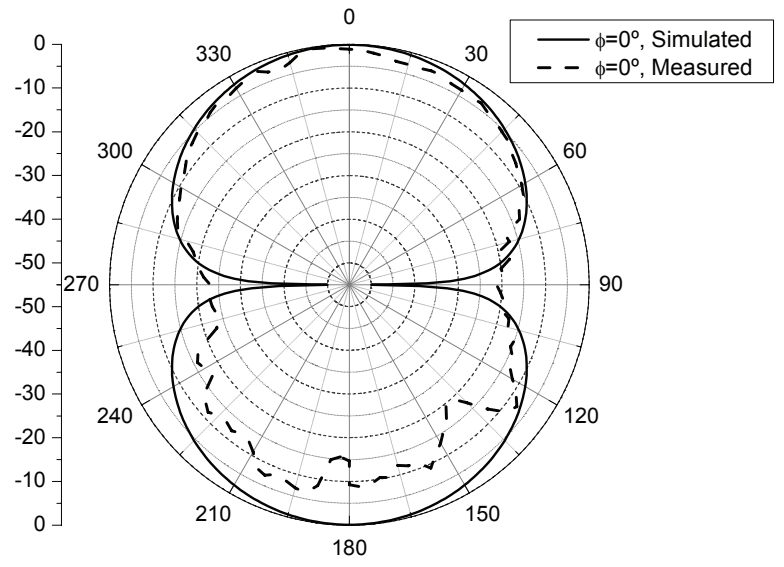

(b)

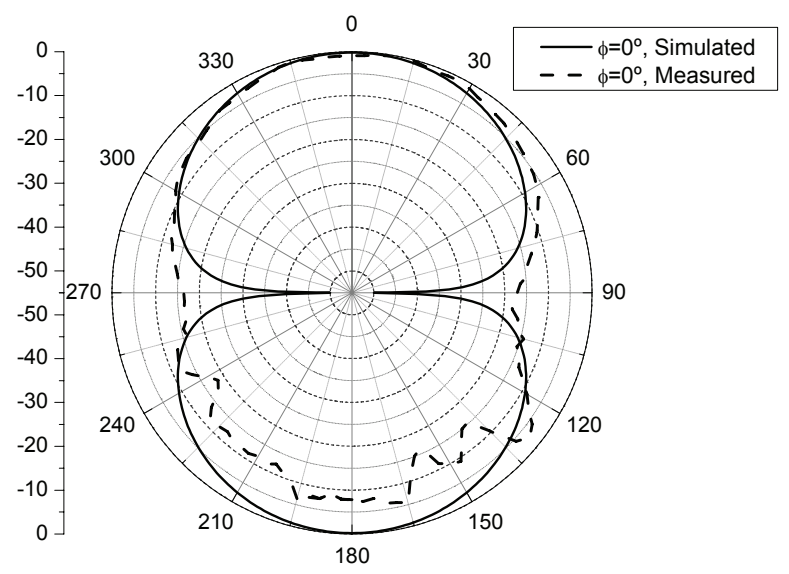

(c)

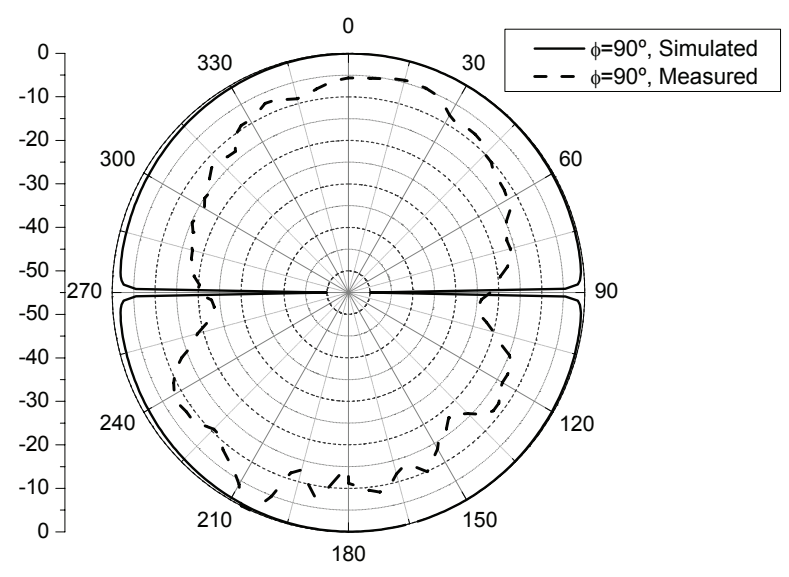

(d)

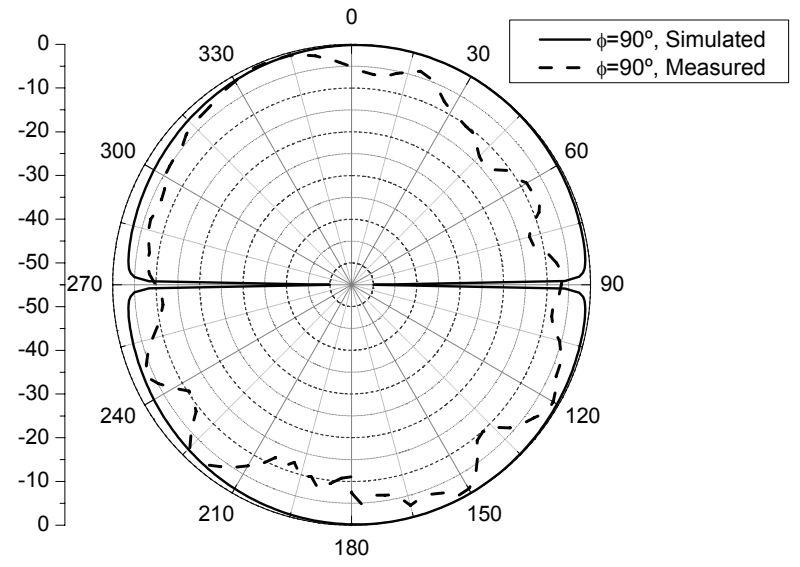

(e)

Fig. 4. Simulated and measured results of the antennas: (a) radiation pattern at $6.5 \mathrm{GHz}, \phi=0$, (b) radiation pattern at $7.5 \mathrm{GHz}, \phi=0$, (c) radiation pattern at 8.5 $\mathrm{GHz}, \phi=0$, (d) radiation pattern at $6.5 \mathrm{GHz}, \phi=90$, and (e) radiation pattern at $8.5 \mathrm{GHz}, \phi=90$.

\section{Efficiency and linearity}

Table 1. Antenna efficiency

\begin{tabular}{lccc}
\hline Frequency $(\mathrm{GHz})$ & 6.5 & 7.5 & 8.5 \\
\hline Simulated $(\%)$ & 93.0 & 92.2 & 91.3 \\
Measured $(\%)$ & 86.0 & 97.2 & 91.1 \\
\hline
\end{tabular}

Table 1 shows antenna efficiency. It is seen that the antenna provides high antenna efficiency throughout the measured frequency-band, i.e., between 86.0 and $97.2 \%$. The antenna efficiency was measured with a wheeler cap. Simulation was conducted on the antenna without balun, with the differential port as reference. The measurement was done when the antenna is fed by the balun, i.e., the single ended port of the balun is the reference. Therefore the antenna efficiency simulation and measurement should be compared with this difference in mind, i.e., this is the reason why maximum measured antenna efficiency can be higher than maximum simulated value. The simulation shows that the antenna efficiency decreases with increased frequency, which is due to increased substrate loss. Moreover, the slightly lower measured value at $6.5 \mathrm{GHz}$ is likely due to the filtering characteristics of the balun [12].

Fig. 5 shows the measured $S_{21}$ phase response from a transmission between two identical antennas, including the contribution from one transmitter antenna and one receiver antenna. It is seen that the established radio link has good phase linearity. A secondary conclusion that can be drawn from the linear phase response is that there is only one dominating phase centre of the radiator, i.e., any possible radiation contribution from the balun is low compared to the contribution from the antenna. 


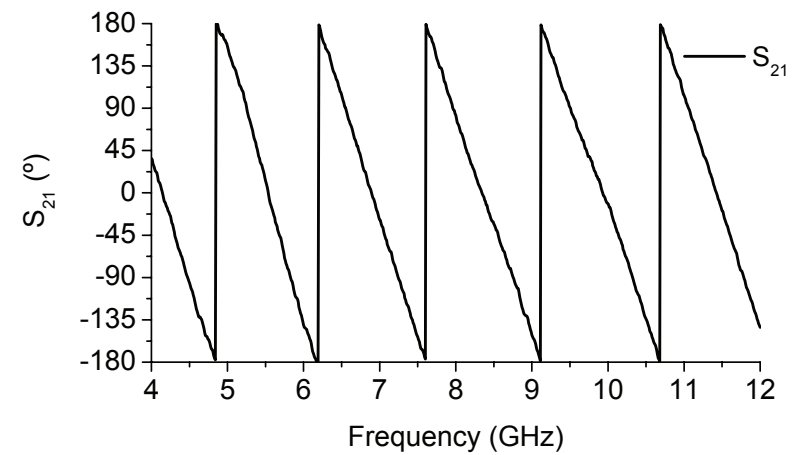

Fig. 5. Measured $S_{21}$ phase response (transmission between two identical circular dipole antennas).

\section{DISCUSSION}

The simulations and measurements of the circular dipole antenna show that the antenna has a typical radiation pattern as expected from a common dipole antenna. Since ADS Momentum cannot handle finite-size substrate, the flexible and the rigid parts were therefore simulated as isolated components. This fact adds constraints to the model accuracy, i.e., balun filtering and antenna-balun coupling effects are not seen in the simulation. The balun has as presented in [12] a bandpass like characteristic. This is good property to reject outbound signals, but it also reduces the antenna efficiency close to the band edges. From radiation point of view a general agreement is seen, but some difference between simulation and measurement is observed for the back-lobe. This is likely due to the fact that the ground-plane of the balun and the grounded metal body of the SMA connector is closer to the propagation path, i.e., the electromagnetic fields couples more in this direction [15], [34].

\section{CONCLUSION}

A circular dipole antenna implemented using the flex-rigid substrate covers the upper UWB band used in Europe (6.0-8.5 $\mathrm{GHz}$ ) at a measured $\mathrm{VSWR}<2.0$. Moreover, the antenna covers 5.5-11.0 GHz at VSWR $<2.5$. Furthermore, good phase linearity is observed when the antenna is used in a wireless transmission test. Finally, high antenna efficiency above $86 \%$ is achieved within the frequency-band. As a result the antenna can be either used as a free-stand component or integrated in a UWB system.

\section{ACKNOWLEDGEMENT}

The authors would like to thank Professor Anders Rydberg at the Department of Engineering Sciences, Microwave Group, Uppsala University for providing radiation measurements.

\section{REFERENCES}

[1] "First report order, revision of part 15 of commission's rules regarding ultra-wideband transmission systems" FCC., Washington, 2002.

[2] G. R. Aiello and G. D. Rogerson, "Ultra Wideband Wireless Systems," IEEE Microwave Magazine, vol. 4, no. 2, pp. 36-47, Jun. 2003.
[3] D. Ghosh, A. De, M. C. Taylor, T. K. Sarkar, M. C. Wicks, E. L. Mokole, "Transmission and Reception by Ultra-Wideband (UWB) Antennas," IEEE Antennas and Propag. Mag., vol. 48, no. 5, pp. 67-99, Oct. 2006.

[4] L. Yang and G. B. Giannakis, "Ultra-Wideband Communications, an Idea Whose Time has Come," IEEE Signal Processing Magazine, pp. 26-54, Nov. 2004.

[5] M. Karlsson, and S. Gong, "Monopole and Dipole Antennas for UWB Radio Utilizing a Flex-rigid Structure," ISAST Transactions on Electronics and Signal Processing, vol. 2, no. 1, pp. 59-63, 2008.

[6] M. Karlsson, J. Osth, Owais, A. Serban, S. Gong, "Circular dipole antennas for lower and upper UWB bands with integrated balun," IEEE International Conference on Ultra-Wideband, ICUWB 2009, pp.658663, 9-11 Sept. 2009.

[7] J. Balakrishnan, A. Batra, and A. Dabak, "A multi-band OFDM system for UWB communication," Proc. Conf. Ultra-Wideband Systems and Technologies, Reston, VA, 2003, pp.354-358.

[8] W. D. Jones, "Ultrawide gap on ultrawideband," IEEE Spectrum, vol. 41, no. 1, pp. 30, Jan. 2004.

[9] D. Geer, "UWB standardization effort ends in controversy," Computer, vol. 39, no. 7, pp. 13-16, July 2006.

[10] W. Hirt, "The European UWB Radio Regulatory and Standards Framework: Overview and Implications," IEEE International Conference on Ultra-Wideband, ICUWB 2007, pp.733-738, 24-26 Sept. 2007.

[11] A. Giorgetti, M. Chiani, D. Dardari, R. Piesiewicz, G. H. Bruck, "The Cognitive Radio paradigm for Ultra-Wideband systems: The European Project EUWB," IEEE International Conference on Ultra-Wideband, ICUWB 2008, vol.2, pp.169-172, 10-12 Sept. 2008.

[12] M. Karlsson, and S. Gong, "Circular Dipole Antenna for Mode 1 UWB Radio with Integrated Balun Utilizing a Flex-rigid Structure," IEEE Trans. Antennas and Propag., vol. 57, no. 10, pp. 2967-2971, Oct. 2009.

[13] S. Chakraborty, N. R. Belk, A. Batra, M. Goel, A. Dabak, "Towards fully integrated wideband transceivers: fundamental challenges, solutions and future," Proc. IEEE Radio-Frequency Integration Technology: Integrated Circuits for Wideband Communication and Wireless Sensor Networks 2005, pp. 26-29, 2 Dec. 2005.

[14] H. Schantz, "The Art and Science of Ultrawideband Antennas," Artech House Inc., ISBN: 1-58053-888-6, 2005.

[15] M. Karlsson, P. Håkansson, A. Huynh, and S. Gong, "Frequencymultiplexed Inverted-F Antennas for Multi-band UWB," IEEE Wireless and Microwave Conf. 2006, pp. 2.1-2.3, 2006.

[16] Z. N. Chen, M. J. Ammann, X. Qing; X. H. Wu, T. S. P. See, A. Cai, "Planar antennas," Microwave Magazine, IEEE, vol. 7, no. 6, pp. 63-73, Dec. 2006.

[17] W. S. Lee, D. Z. Kim, K. J. Kim; K. S. Son, W. G. Lim, J. W. Yu, "Multiple frequency notched planar monopole antenna for multi-band wireless systems," Proc. IEEE 35th European Microwave Conf., Paris, France, pp. 535-537, Oct. 2005

[18] X. H. Wu, Z. N. Chen, "Comparison of planar dipoles in UWB applications," IEEE Trans. Antennas and Propag., vol. 53, no. 6, pp. 1973-1983, Jun. 2005.

[19] T.-G. Ma, S.-K. Jeng, "A printed dipole antenna with tapered slot feed for ultrawide-band applications," IEEE Trans. Antennas and Propag., vol. 53, no. 11, pp. 3833-3836, Nov. 2005.

[20] R. Bourtoutian, C. Delaveaud, S. Toutain, "Differential, Shorted Dipole Antenna for European UWB Applications," The Second European Conference on Antennas and Propagation, EuCAP 2007, pp.1-5, Nov. 2007.

[21] J.-P. Zhang; Y.-S. Xu, W.-D. Wang, "Microstrip-Fed Semi-Elliptical Dipole Antennas for Ultrawideband Communications," IEEE Trans. Antennas and Propag., vol. 56, no. 1, pp. 241-244, Jan. 2008.

[22] C.-D. Zhao, "Analysis on the properties of a coupled planar dipole UWB antenna," IEEE Antennas and Wireless Propag. Lett., vol.3, no., pp. 317-320, 2004.

[23] B. Kim, S. Nikolaou, G. E. Ponchak, Y.-S. Kim, J. Papapolymerou, M. M. Tentzeris, "A curvature CPW-fed ultra-wideband monopole antenna on liquid crystal polymer substrate using flexible characteristic," IEEE Antennas and Propagation Society Int. Symp. 2006, pp. 1667-1670, 9-14 Jul. 2006.

[24] J. S. McLean, H. Foltz, R. Sutton, "Pattern descriptors for UWB antennas," IEEE Trans. Antennas and Propag., vol. 53, no. 1, pp. 553559, Jan. 2005. 
[25] J. McLean, H. Foltz, R. Sutton, "Conditions for Direction-Independent Distortion in UWB Antennas," IEEE Trans. Antennas and Propag., vol. 54, no. 11, pp. 3178-3183, Nov. 2006.

[26] T. Dissanayake, K. P. Esselle, "Prediction of the Notch Frequency of Slot Loaded Printed UWB Antennas," IEEE Trans. Antennas and Propag., vol. 55, no. 11, pp. 3320-3325, Nov. 2007.

[27] D. Valderas, R. Alvarez, J. Melendez, I. Gurutzeaga, J. Legarda, J. I. Sancho, "UWB Staircase-Profile Printed Monopole Design," IEEE Antennas and Wireless Propag. Lett., vol. 7, pp. 255-259, 2008.

[28] M. E. Bialkowski, A. M. Abbosh, "Design of UWB Planar Antenna With Improved Cut-Off at the Out-of-Band Frequencies," IEEE Antennas and Wireless Propag. Lett., vol. 7, pp. 408-410, 2008.

[29] W. Wiesbeck, G. Adamiuk, C. Sturm, "Basic Properties and Design Principles of UWB Antennas," Proc. of the IEEE, vol. 97, no. 2, pp. 372-385, Feb. 2009.

[30] J. R. Costa, C. R. Medeiros, C. A. Fernandes, "Performance of a Crossed Exponentially Tapered Slot Antenna for UWB Systems," IEEE Trans. Antennas and Propag., vol. 57, no. 5, pp.1345-1352, May 2009.

[31] Y. Duroc, A. I. Najam, T. P. Vuong, S. Tedjini, "Modeling and State Representation of Ultrawideband Antennas," IEEE Trans. Antennas and Propag., vol. 57, no. 9 , pp. 2781-2784, Sept. 2009.

[32] B. S. Yildirim, B. A. Cetiner, G. Roqueta, L. Jofre, "Integrated Bluetooth and UWB Antenna," IEEE Antennas and Wireless Propag. Lett., vol. 8, pp. 149-152, 2009.

[33] K. S. Ryu, A. A. Kishk, "UWB Antenna With Single or Dual BandNotches for Lower WLAN Band and Upper WLAN Band," IEEE Trans. Antennas and Propag., vol. 57, no. 12, pp. 3942-3950, Dec. 2009.

[34] V. F. Fusco, "Foundations of Antenna Theory and Techniques," Edinburgh Gate, Harlow, Essex, England, Pearson Education Limited, pp. $45,2005$.

[35] M. Karlsson, P. Hakansson, S. Gong, “A Frequency Triplexer for UltraWideband Systems Utilizing Combined Broadside- and Edge-Coupled Filters," IEEE Trans. on Advanced Packaging, vol. 31, no. 4, pp. 794801, Nov. 2008. 